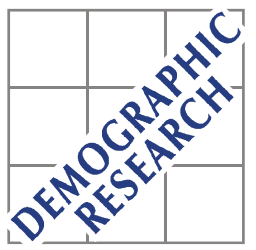

Demographic Research a free, expedited, online journal of peer-reviewed research and commentary in the population sciences published by the Max Planck Institute for Demographic Research Konrad-Zuse Str. 1, D-18057 Rostock · GERMANY www.demographic-research.org

DEMOGRAPHIC RESEARCH

VOLUME 11, ARTICLE 15, PAGES 421-454

PUBLISHED 23 DECEMBER 2004

www.demographic-research.org/Volumes/Vol1 1/15/

DOI: 10.4054/DemRes.2004.11.15

Descriptive Findings

\title{
Childbearing patterns for Swedish mothers of twins, 1961-1999
}

\section{Jan M. Hoem \\ Margit Strandberg}

(C) 2004 Max-Planck-Gesellschaft. 


\section{Table of Contents}

1 Introduction 422

2 Twins in the literature; historical trends in Sweden 423

3 Our data and method of analysis 425

$4 \quad$ Twinning at first birth 426

5 Mothers of a pair of twins and mothers of one singleton $\quad 428$

6 Mothers of a pair of twins and mothers of two singletons 429

$7 \quad$ The third birth to mothers of twins 429

8 Conclusions 430

9 Acknowledgements 430

$\begin{array}{ll}\text { Notes } & 431\end{array}$

$\begin{array}{ll}\text { References } & 434\end{array}$

$\begin{array}{ll}\text { Tables and figures } & 438\end{array}$ 
Descriptive Findings

\title{
Childbearing patterns for Swedish mothers of twins, 1961-1999
}

\author{
Jan M. Hoem ${ }^{1}$ \\ Margit Strandberg ${ }^{2}$
}

\begin{abstract}
The Nordic population registers provide a unique possibility to study the demographic behavior of very small population groups and rare events. In this paper, we study the childbearing behavior of Swedish mothers of twins between 1961 and 1999, inclusive. Our most consistent finding is that mothers of twins wait noticeably longer than women with singletons before they have another child. This apart, mothers with twins at their first birth have next-birth fertility patterns very similar to women who have two singletons at their first two births. This commonality in childbearing behavior does not extend to higher-order births. For mothers with a singleton and a pair of twins, the progression to a third birth depends very much on whether the twins came first or second.

Beside these main results our fascinating material also provides a number of descriptive findings. The Swedish twinning rate has increased since the mid-1970s in response to a growing use of fertility-stimulating treatments such as in-vitro fertilization, in parallel with similar developments in many other countries. Such medical procedures are applied mainly to women beyond prime childbearing ages. Nevertheless, we find no simple age pattern in twinning rates. Even in recent years they do not just increase with the woman's age. By way of contrast, at parities beyond 3, twinning rates increase with parity when we control for calendar period, time since last previous birth, and (NB) the woman's own age.
\end{abstract}

\footnotetext{
1 Max Planck Institute for Demographic Research, Konrad-Zuse-Straße 1, D-18057 Rostock, Germany, hoem@demogr.mpg.de

2 Valhallavägen 12 B, S-114 22 Stockholm, Sweden, margit.strandberg@ comhem.se.
} 


\section{Introduction}

While the literature is rich in studies of the behavior of twins, or of features like their mortality, very little seems to be known about the demographic behavior of the parents of twins. Realizing that the sheer work involved in raising a young pair of twins must be much harder than raising one or two singletons, careful demographers have long suspected that parents of twins have patterns of childbearing and family dynamics that differ from others, and they therefore censor life histories at the arrival of twins. The present paper shows that this is sensible practice, at least for Swedish women between the 1960s and 1990s. Since only about one per cent of births resulted in twins, the loss of information must be negligible in normal investigations of childbearing behavior.

Since twinning is a relatively rare event, special types of data sets are needed for studies of the detailed patterns of behavior of parents of twins, preferably extensive databases like the Nordic population registers (Note 1). The advantage of the complete coverage that they give is that they allow us to map patterns of the demographic behavior even of very small groups and very rare events. In parallel with Walke's investigation of divorce risks for Swedish parents of twins (Walke, 2002) based on the same data, we tap this exciting data source for information about the childbearing behavior of Swedish mothers of twins in the last forty years of the twentieth century. Most of our report contains a comparison between mothers of twins and mothers of one or two singletons.

Our main new findings, and our corresponding interpretations, are as follows:

(1) The second-birth fertility of women whose first birth resulted in twins is much lower than for corresponding mothers with a singleton first birth but it remained roughly at the same level as the third-birth fertility of mothers of two singletons. What counts is the number of children born, not the number of births needed to attain it.

(2) The most important difference between the two groups of women is that mothers of twins wait noticeably longer before they have another child than women with a second singleton do. As we noted, raising twins is much more burdensome than raising one or two singletons, and this is reflected in the waiting time.

(3) Trends in the fertility of mothers of twins largely follow those for mothers of singletons. Similarly rates of twin first births largely follow those for singleton first births. Since twins surely mostly come as a surprise, conception rates of twin and singleton births should move in unison, and any difference in birth rates would be produced by differential fetal loss and selective abortion. One feature interferes in this parallelism, namely an independent upward trend in twinning rates caused by medical interference to help women who have difficulty conceiving.

(4) For mothers with a singleton and a pair of twins, the progression to a third birth depends very much on whether the twins came first or second. At each stage after the 
second birth, mothers who had the twins first have much the higher fertility. Presumably this partly reflects the effect of the age of the twins, in that proceeding to a third birth becomes easier as the twins become older. A further partial explanation may be that women in these two groups have different mixes of stopping rules (Note 2). As we noted above, surely no one actively plans to have twins, so women who first had a singleton and then were surprised by a twin birth presumably have a greater fraction planning to stop after two children, and if not then to stop after three. Women who had the twins first and then a singleton have already proceeded to parity 3 and probably have a greater (albeit small) fraction willing to continue up to a fourth child (Note 3).

(5) Our main concern is the fertility of mothers of twins, but we cannot resist also reporting briefly on a couple of other features that have already appeared in the literature. First, many previous authors convey a strong impression that twinning rates increase with the woman's age. This feature is only partly confirmed by our data. We find that the twinning rate does increase up to ages in the thirties but that it actually falls at higher ages. We cannot find any simple relation between twinning and age (Note 4). Second, a corresponding notion that the twinning probability increases with a woman's parity turns out to be present in our population for parities above 3, but not for lower parities. Both of these patterns appear when we control for the converse covariate. Such simple descriptive facts should be taken into account in future theorizing about the effect of age and parity on twinning rates.

Our main business is to document the statements in items (1) through (4) above. To put these findings into perspective, however, we first provide a brief account of trends in twin births in Sweden.

\section{Twins in the literature; historical trends in Sweden}

The previous literature on twins has two main parts. In by far the greater part, the authors explore the behavior of twins, or their morbidity or mortality (Note 5), often thinking in terms of twins as natural experiments. Some typical examples of the latter are Rosenzweig and Wolpin (1980), Grogger and Bronars (1993), Bronars and Grogger (1994), and Behrman et al. (1994) (Note 6).

In a second main part of the literature the focus is on the twinning rate, estimated as the fraction of births that are twin births. Typically, patterns and differentials in such rates across populations are described, and trends over time are given. In most previous studies, the data have only permitted description of period-specific rates by age or occasionally by parity (Note 7). As we shall see below, we have the advantage of being able to include all three of these covariates (age, period, and parity) simultaneously. Our main interest is the childbearing behavior of mothers of twins, not the behavior or fate 
of the twins themselves. Because we can add to the previous literature with very little effort, however, we also include presently some information on twinning rates by current parity and later a section on twinning rates at first birth (Section 4 below). In each case we control for the other covariates.

The fraction of births that were twin births was very stable at 14 per 1000 total births each year for more than fifty years after 1870 (Figure 1). It then declined gradually to about 8 per 1000 in the 1970 s, whereafter it rapidly rose to almost twice that level by the end of the twentieth century, surely mainly as a consequence of medical fertility-stimulating measures used to help childless women. Murphy et al. (1997, 1998) found the same valley-form in data for Great Britain and displayed a chronological coincidence of medical sub-fertility treatment and the rise in birth multiplicity since the 1970s. Tas (1994) and Steegers-Theunissen et al. (1998) have reported similar findings for the Netherlands. A good number of further sets of national twinning rates, many with similar patterns, were given by Eriksson et al. (1995) and by Oleszczuk et al. (1999). The latest contribution with such a pattern known to us is that of Terzera (2002).

The increase in Swedish twinning rates through the 1980s and 1990s was also reflected in the number of children born. In the 1970s, some 1800 twins were born in Sweden each year; two decades later, there were about 3000 (Note 8). By comparison, the number of triplet births was as low as some ten per year during the 1960s and 1970s. In the 1980s, it increased to about thirty per year and reached a record high of sixty in 1993. By the end of the 1990s, the number of triplet births had declined again to around twenty. During the late 1980s and early 1990s, Sweden had an occasional quadruplet birth.

Eriksson and Fellman (1967a, 1967b, 1973; Fellman and Eriksson, 1993; Eriksson et al. 1995) have analyzed early twinning trends in the Nordic countries extensively. During the nineteenth and early twentieth century, Nordic twinning rates were among the highest in the world. The authors found particularly high rates in isolated population groups where a high level of intermarriage was recorded. When migration increased and intermarriage decreased correspondingly, twinning rates declined, a finding that the authors interpret as a reflection of the genetic nature of twinning "risks". Eriksson and Fellman (1973) regarded twinning as being correlated positively with the mother's age at childbearing in general and noted that twinning rates decreased in parallel with the mean childbearing age. Correspondingly, recent Swedish statistics show that the mean age at a twin birth is one to one-and-a-half year higher than that of a singleton birth (Figure 2). However, the twinning rate (Note 9) is particularly high for women in their thirties and it falls at higher ages (Figure 3), as has also been shown by Fellman and Eriksson (1993) (Note 10). There does not seem to be any simple monotonic relation 
between twinning and age. Nevertheless, a changing age structure at childbearing may easily contribute to the drop recorded between the 1930s and ca. 1970 in Figure 1.

Some authors have also reported a positive association with the woman's parity (Pollard, 1969; for a discussion see Högberg and Wall, 1992). We find this to be true at parities above 3 (Figure 4) (note 11) and note that a reduction of fertility at higher parities may therefore be another part of the explanation of the drop in Swedish twinning rates up to about 1970 , since fertility declined at higher parities during this time. The common view seems to be, however, that a changing composition of the set of childbearing women by age and parity is insufficient to explain completely the reduction in the twinning rate (Note 12). Our own experiments (not displayed here, but see Figure 4 in Strandberg and Hoem, 2002) also show that the Swedish twinning rate increased considerably in the last quarter of the twentieth century even when we control for the changing age distribution among mothers. Evidently, new features have entered into the picture. The standard explanation in the literature is that in-vitro fertilization is a main factor in this development (Note 13). Such treatment is normally administered to women of a relatively high age and only after they have undergone long periods of tests (Note 14). This practice alone would contribute to a relatively high age at twin birth.

\section{Our data and method of analysis}

We have the advantage over most other students of twinning that we have individuallevel data from a large population at our disposal. Our data come from the Swedish population register and cover every Swedish woman recorded in the years 1961 through 1999. The data contain her own birthdate and the dates of each of her births. Each woman's record is censored at her death or first emigration and at the end of 1999. Our source data include liveborn children only. This means that a stillbirth is not recorded and that a twin birth is counted as a singleton birth if only one child was liveborn.

We analyze our data mostly by means of a multivariate generalization of classical standardization methods. For each birth order we use a competing-risks intensity model (Note 15) of the form $\mu_{k x}^{(h)}=\theta c_{k h} a_{x h}$, where in calendar period $k \mu_{k x}^{(h)}$ is the "risk" of having a birth of multiplicity $h$ for a woman currently in age group $x$ (Note 16). Because of the scarcity of births of multiplicity 3 or higher, we operate with $h=1$ or 2 and censor a record at any birth of multiplicity above 2 . To achieve identification, we let $c_{k_{0} 1}=1$ for a suitable $k_{0}$ and $a_{x_{0} 1}=1$ for a suitable $x_{0}$. With these conventions, $\theta$ represents the intensity of a singleton birth for a woman at age $x_{0}$ in period $k_{0}$. 
The birth multiplicity $h$ appears in this model in interaction with each of the covariates $x$ and $k$ at the same time. Our reasoning is based on this model. Because it has been much more practical for us and easier to report, we have often fitted models with a simpler interaction structure, as noted in each case below. We pay some attention to strengths and weaknesses of this method of analysis in Section 4 below.

All tables in this paper contain maximum-likelihood estimates of model parameters computed from our data. Figures 1 through 3 are based on population statistics in annual publications from Statistics Sweden. Figure 4 is the result of our own calculations based on the Swedish population register, as are all subsequent diagrams.

In a data set as large as ours, most differences shown turn out to be statistically significant at all normal significance levels, even when they have little substantive content, and normal tests lose their meaning (Note 17). In line with the general policy of this journal, we therefore do not report anything about statistical significance in this paper.

\section{Twinning at first birth}

Since 1961, Swedish fertility has gone through what Hoem and Hoem (1996) have called a roller-coaster development. It can be depicted in various ways; in Figure 5 we show it in the form of a series of age-standardized annual intensities (hazards) for singleton first births and a corresponding series for twin first births, using the level in 1990 as a baseline for each curve separately. We see that the two series run largely parallel until the early 1980s, after which the series for twin births has its own upward impetus. This is what we would expect, given that a twin birth most often would come as a surprise, except possibly after medical intervention. (In-vitro fertilizations are used most often for childless women.) If we turn to relative risks, we find that the twin-birth "risk" of a childless Swedish woman was some 0.6 to 0.7 per cent of the corresponding singleton-birth intensity during the first two decades after 1961, but the relation then changed and the relative risk increased to almost 2 per cent by the end of the 1990s (Note 18). Figure 6 shows to what extent the age profile of twin first births is shifted towards somewhat higher ages (Note19).

Figures 5 and 6 are based on Table 1, the two main panels of which contains maximum-likelihood estimates of the parameters of two simplified versions of the intensity model $\mu_{k x}^{(h)}=\theta c_{k h} a_{x h}$ described above. The two columns of the first panel

contain estimates $\hat{c}_{k h}$ of the relative risks $c_{k h}$ in the model $\mu_{k x}^{(h)}=\theta c_{k h} a_{x}$ (for $h=1,2$ ), 
and the two columns of the second panel contain estimates $\hat{a}_{x h}$ of the relative risks $a_{x h}$ in the model $\mu_{k x}^{(h)}=\theta c_{k} a_{x h}$ (again for $h=1,2$ ). This means that we have operated with one "interaction" with the birth multiplicity at a time. For our purpose, this is a sufficiently accurate approximation (Note 20).

To better see the trend across periods in the twinning risk, we have plotted the sequence $\left\{\hat{c}_{k h} / \hat{c}_{1990, h}\right\}$ against $k$ in Figure 5, separately for $h=1$ and $h=2$. In Figure 6 we have plotted the sequence $\left\{\hat{a}_{x h} / \hat{a}_{28, h}\right\}$ against $x$, again separately for singleton and twin first births, to better see the age pattern in the twinning risk.

In order to estimate the general fertility level in our data we have fitted the model $\mu_{k x}^{(h)}=\theta m_{h} c_{k} a_{x}$ with $m_{1}=1$ and find $\hat{\theta}$ to be 5.3 per 10000 person-months of exposure, standardized for multiplicity, period, and age group. The corresponding relative risk of having twins in a first birth, standardized for period and age, is $\hat{m}_{2}=0.0093$. This figure is given above the first main panel in Table 1 (to the accuracy of four decimals). A similar descriptive estimate is given above the first main panel in all subsequent tables where relevant.

Our use of multiplicative models is a descriptive device that neatly distills main features of a complex data set and allows us to display them. It would be harder to bring out those features by other methods. Our procedure has the disadvantage that it does not pick up the manner in which twin-birth intensities have developed differentially at different ages since the early 1980s. In reflection of this, Figure 7 (Note 21) shows how twin-birth intensities have increased at ages 31-33 and 40-42 since 1982-84, and even more strongly at the ages in between, while they have actually decreased at ages below 25 (Note 22). To reflect such features also, we need an interaction between age $x$ and calendar year $k$ in our intensity models. When we leave out that interaction in order to avoid cluttering up the descriptions, we run the risk that the features we display are warped, because we actually work with a mis-specified model. To hedge against warped results, we have carried out extensive experiments where we have fitted our multiplicative models separately to the data for periods before and after the early 1980s. The outcome of some of those experiments have been reported by Strandberg and Hoem (2002) in their Figures 15 through 17, and further diagrams can be requested from the present authors. These experiments convince us that the features we display actually serve the purpose intended, and that they are not subject to any important warping. 


\section{Mothers of a pair of twins and mothers of one singleton}

We now turn to our main topic, namely the fertility of mothers of twins. In our analysis we estimate simultaneously two competing risks again, this time (i) the intensity of having a singleton second birth and (ii) the corresponding intensity for a twin second birth. As in Section 4, we use a standard multiplicative intensity model for each risk, now of the format $\mu_{i j k t}^{(h)}=\theta a_{i j} b_{j h} c_{k j} d_{t j}$. The index $h$ is used for the multiplicity of the second birth. Our covariates are (1) the woman's age group at first birth, indexed by $i$, (2) the multiplicity of the first birth, now indexed by $j$, and (3) the current calendar period (regarded as a time-varying covariate), indexed by $k$ and grouped as in Table 3, which contains our maximum-likelihood estimates of our parameters, except that estimates $\hat{b}_{j h}$ of the relative risks $b_{j h}$ are given in Table 2 (Note 23). Our duration variable $t$ is time since first birth, grouped as also shown in Table 3 (last main panel). The analysis applies to women born in Sweden with a first birth of multiplicity 1 or 2 . (We have left out the few women who had first births of multiplicity above 2.) To ensure parameter identification, we have set $b_{11}=1$, precisely one of the $a_{i j}$ is also set to 1 , and so on. This means that the parameters represent relative risks.

We estimate the rate of arrival of a second birth for mothers who first had twins to be 0.342 relative to the rate for mothers who first had a singleton birth, standardizing for age at first birth, for calendar period, and for first-birth multiplicity. This means that on average, mothers who delivered twins at their first birth have only about one-third as high an intensity for a second birth as mothers whose first confinement resulted in a single child. We have also found that $\hat{b}_{21}=0.338$ (Table 2). This is our estimate for the relative risk of having a singleton at the second birth when the mother had twins in her first delivery.

In addition, we estimate $\hat{b}_{12}=0.010$ and $\hat{b}_{22} / \hat{b}_{21}=0.022$ (Note 24). The latter figure means that if these women have a second birth, mothers whose first delivery resulted in twins have about twice as high a chance of giving birth to twins again as women whose first delivery resulted in a singleton (Note 25). This may constitute further evidence of a genetic component in birth twinning.

The first panel in Table 3 contains our estimates $\left\{\hat{c}_{k j}\right\}$. It displays the trends in our second-birth intensities across calendar periods. The intensities are given relative to that for mothers who delivered a singleton at the first birth in 1988-1990. In order to compare their "pure" time trends without interference from their differences in level, we have plotted the second-birth intensities relative to the corresponding intensity for 
1988-1990 for each first-birth outcome separately in Figure 8. We see that the intensities for a second birth largely have followed the same trends, irrespective of the outcome of the first birth. The most obvious deviations are the much stronger decline in second-birth intensities for mothers of twins between 1965 and 1975, and again after the early 1990s. Meanwhile, the characteristics of twin mothers as a group have changed. In the later period, a greater fraction of them consists of women who have had difficulties getting pregnant and who have had their twins after medical intervention.

In the second panel of Table 3 we display the effect of the age of the mother at first birth, and the final panel in Table 3 as well as Figure 9 shows the extent to which the second-birth intensity for mothers of twins and singletons depends on the duration since their first confinement. We see that mothers of twins have much the lower next-birth intensity and that in general they wait longer before they have another birth. None of this is surprising. Given the strong two-child norm in Sweden, many of the mothers of first-birth twins must have reached their family-size goal, so on average mothers of twins should have a lower propensity to proceed to a second birth than mothers of a first-birth singleton. The progression should also be slower, again given the greater strain of raising twins than a singleton child.

\section{Mothers of a pair of twins and mothers of two singletons}

Perhaps a more equitable comparison is that of the next-birth intensity of a mother of twins and a comparable mother of two singletons. Both have two children, so we will now compare birth intensities for the third child, taking into account the manner in which parity 2 was attained. Parameter estimates of intensity models similar to those in our previous section are given in Table 4. Let us start by noting that the two groups we now study largely have the same next-birth fertility, and that the trends of each group across calendar time are very close to each other (Figure 10). Once more, twin mothers tend to wait longer before they venture into their next birth than mothers of two singletons do (Figure 11). This apart, the two groups have remarkably similar fertility.

\section{The third birth to mothers of twins}

We now turn to third births for women who previously have had twins either in their first or second delivery (Note 26). It turns out that there is a considerable difference in childbearing behavior between women whose twin birth came first and those whose twin birth came second (Table 5). All in all, the first group has had a much higher (Note 27) third-birth intensity than the second on average, perhaps for two reasons. First, the 
two groups must be quite differently composed according to lifetime childbearing plans, as we discussed under item (4) in our introduction and do not repeat here. Second, if the twins came at the first birth, they are older and the situation is therefore more manageable at each stage after the second birth than when the twins came in the second delivery. This shows up in Figure 12, which shows that fertility differences between the two groups diminish as the child's age increases (Note 28). Surely, the age of the twins is the driving element in this decrease in the relative birth "risks".

The age of the mother does not seem to have much systematic impact on the thirdbirth intensities, but the difference between them was smaller in the 1960s than thereafter (Note 29). Since more women were housewives in our first period than in the later ones, we speculate that having a third birth was more manageable than later on even when one of the previous births had resulted in twins.

\section{Conclusions}

The main contribution of this paper is a mapping of patterns of childbearing behavior by mothers of twins. Our results reflect the obvious expectation that childbearing behavior is dominated by the number of children a woman has had or plans to have, not by the number of confinements used to produce those children. We also show that parents of twins wait longer than comparable parents of singletons do before they proceed to any subsequent birth, presumably because of the greater strain of raising twins. Both of these features correspond to simple common sense and to what demographers have long suspected, but as far as we know they are documented here for the first time. As a by-product we show that twinning rates in Sweden have developed over time in parallel with the introduction and use of medical interventions like in-vitro fertilization, just like in many other populations. Furthermore we show that there is a simple but non-monotonic association between age and twinning when one controls for parity, and also a non-monotonic association between parity and twinning when one controls for the mother's age. We believe that we have provided a sharper description of the latter patterns than what is available in the previous literature.

\section{Acknowledgements}

The comments of three anonymous reviewers have been most helpful in our work with this paper. We are also grateful for Susann Backer's most competent help with language editing. 


\section{Notes}

1. Madrigal (1995) has used a much smaller data set $(n=149)$ to study the ultimate fertility of mothers of twins and mothers of singletons.

2. We owe this interpretation to an anonymous reviewer.

3. Since people's preferences must be for a number of children and not for a number of births, the early supermortality of twins could disturb this picture (since in our analysis we do not change a mother's recorded parity at the death of a child), but we believe that it only plays a limited role for our results.

4. Corresponding non-monotonicities have been reported by Fellman and Eriksson (1993) and Eriksson et al. (1995).

5. See, for instance, Andreasson and Brandt (1997) and Baird et al. (1998).

6. Extensive activities in this line at the Max Planck Institute for Demographic Research in recent years have resulted in output by Yashin et al. (1998, 1999a, 1999b), Iachine et al. (1998, 1999a, 1999b), Christensen et al. (2000, 2001, 2003), Tomassini et al. (2001), Rogers et al. (2001), Kohler et al. (1999, 2000, 2001, 2002), and Wienke at al. (2001, 2002).

7. Murphy et al. $(1997,1998)$ and others use data specified by age of mother and mono- or polyzygoticity of children but do not include parity in their analysis. Some authors, like James (1995), also include the woman's marital status.

8. Note that these numbers indicate the sample size for our study of the childbearing behavior of mothers of twins.

9. Note that the twinning rate is the fraction of twins among the births. This is something else than the various twin-birth intensities that we present in what follows. A twin-birth intensity is the rate at which women have twin confinements; the twinning rate is the conditional probability that the confinement results in twins, given that there is a confinement.

10. They found a similar pattern by age in triplet rates as well.

11. The relative risks of a twin birth in Figure 4 are for mothers who have only had singleton births up to each given parity. The risks have been standardized for calendar period, the woman's age group at last previous birth, and for months since last previous birth. Since the latter covariate has no meaning before second birth, first births are not included in the diagram. The maximum likelihood estimates in Figure 4 are computed by a method quite similar to what we explain below; we do 
not include an explanation here. See Strandberg and Hoem (2002) for more detailed results.

12. See, e.g., Eriksson et al. (1995).

13. See, e.g., Murphy et al. (1997).

14. See, e.g., Lundin (1996). The first children born in Sweden after in-vitro fertilization were delivered in 1982 (Socialstyrelsen, 1998).

15. See Hoem (1987) for a general theory of such simple multiplicative intensity models.

16. We mostly use three-year calendar periods and three-year age groups, as displayed in our tables.

17. In the current setting, the likelihood-ratio test is the natural statistic to use.

18. In the first panel of Table 1, divide the item in the second column by the corresponding item in the first column to get these figures.

19. Note how Figure 6 picks up an aspect of twinning different from that of Figure 3. The difference is that between twin-birth intensities and twinning rates, described in Note 9.

20. We have used a corresponding procedure for all parameter estimates in our subsequent tables and diagrams.

21. We have deleted some in-between age groups so as not to clutter up the diagram needlessly. The curves for the deleted age groups truly lie between the curves we have included.

22. Corresponding trends in age-specific twinning rates appear in Figure 3 in Strandberg and Hoem (2002).

23. Note that the first subscript in $b_{j h}$ represents the multiplicity of the first birth and the second subscript the multiplicity of the second birth.

24. The latter value is based on a computation using more decimals than those shown in Table 2.

25. In our material, 122 mothers who delivered twins at their first birth also had twins at their second birth. The numbers are small, nevertheless the size of our data set and the sensitivity of our method of analysis permits us to make interesting findings like this. 
26. In our data, no woman who had two twin births ever had a third birth, so there is no need to study third births in this group.

27. Our estimate of the relative risk is 1.982, i.e., the former group had about twice as high an intensity as the latter. See just above the first main panel in Table 5.

28. To get the ordinates of the curves in Figure 12 proceed as follows: Locate the two columns of estimates in the third main panel in Table 5. Divide each item in the second column by the corresponding item in the first column. This gives the ordinates on the upper curve in Figure 12. Use the ordinate 1 for all points on the lower curve.

29. See the first two panels of Table 5 . 


\section{References}

Andreasson, Sven and Lena Brandt (1997). Mortality and morbidity related to alcohol. Alcohol and alcoholism 32 (2), 173-178.

Baird, Janis, Clive Osmond, Ian Bowes, David I. W. Philips (1998). Mortality from birth to adult life: a longitudinal study of twins. Early Human Development 53 (1): 73-79.

Behrman, Jere R., Mark R. Rosenzweig, and Paul Taubman (1994). Endowments and the allocation of schooling in the family and in the marriage market: the twins experiment. Journal of Political Economy 102 (6): 1131-1173.

Bronars, Stephen G. and Jeff Grogger (1994). The economic consequences of unwed motherhood: using twins as a natural experiment. American Economic Review 85 (5): 1141-1156.

Christensen, K.; M. McGue, A. I. Yashin, I. A. Iachine, N. V. Holm, and J. W. Vaupel (2000). Genetic and environmental influences on functional abilities in Danish twins aged 75 years and older. Journal of Gerontology: Medical Sciences 55A (8): M446-M452.

Christensen, K., A. Wienke, A. Skytthe, N. V. Holm, J. W. Vaupel, and A. I. Yashin (2001). Cardiovascular mortality in twins and the fetal origins hypothesis. Twin Research 4 (3): 344-349.

Christensen, K., H.-P. Kohler, O. Basso, J. Olsen, J. W. Vaupel, and J. L. Rodgers (2003).The correlation of fecundability among twins: evidence of a genetic effect on fertility? Epidemiology 14:1, 60-64.

Eriksson, Aldur W., and Johan Fellman, (1967a). Twinning and legitimacy. Hereditas 57: $395-402$

Eriksson, Aldur W., and Johan Fellman, (1967b). Twinning in relation to marital status of the mother. Acta Genetica et Statistica Medica 17: 385-398.

Eriksson, Aldur W., and Johan Fellman (1973). Differences in the twinning trends between Finns and Swedes. The American Journal of Human Genetics 25 (2): $141-151$.

Eriksson, A. W., C. Abbot, P. Kostense, J. O. Fellman (1995). Secular changes of twinning rates in Nordic populations (1995). Acta geneticae medicae et gemellologiae 44: 141-162. 
Fellman, Johan O. and Aldur W. Eriksson (1993). Biometric analysis of the multiple maternities in Finland, 1881-1990, and in Sweden since 1751. Human Biology 65 (3): 463-479.

Grogger, Jeff and Stephen Bronars (1993). The socioeconomic consequences of teenage childbearing: findings from a natural experiment. Family Planning Perspectives 25 (4): 156-161 and 174.

Hoem, Britta and Jan M. Hoem (1996). Sweden's family policies and roller-coaster fertility. Journal of Population Problems (Tokyo) 52 (3-4): 1-22.

Hoem, Jan M. (1987). Statistical analysis of a multiplicative model and its application to the standardization of vital rates: A review. International Statistical Review 55: 119-152.

Högberg, Ulf, and Stig Wall (1992). Secular trends of twinning rates in Sweden. Journal of Biosocial Science 24 (4).

Iachine, I. A., N. V. Holm, J. R. Harris, A. Z. Begun, M. K. Iachina, M. Latinen, J. Kaprio, and A. I. Yashin (1998). How heritable is individual susceptibility to death? The results of an analysis of survival data on Danish, Swedish and Finnish twins. Twin Research 1 (4): 196-205.

Iachine, I. A., K. Christensen, and A. I. Yashin (1999a). Incorporating genetic marker information into the analysis of twin survival data: a simulation study. Odense: Odense University Press.

Iachine, I. A. and A. I. Yashin (1999b). Bivariate quadratic hazard model: results of analysis of the Danish twins survival data. Odense: Odense University Press.

James, William H. (1995). Are "natural" twinning rates continuing to decline? Human Reproduction 10 (11): 3042-3044.

Kohler, H.-P. J. L. Rodgers, and K. Christensen (1999). Is fertility behavior in our genes: findings from a Danish twin study. Population and Development Review 25 (2): 253-288.

Kohler, H.-P. and K. Christensen (2000). Genetic influences on fertility behavior: findings from a Danish twin study. In: Rodgers, J. C., D. C. Rowe, and W. B. Miller (eds.): Genetic influences on fertility and sexuality. Dordrecht: Kluwer Academic Press: 67-84.

Kohler, H.-P. and J. L. Rodgers (2001). DF-analyses of heritability with double-entry twin data: asymptotic standard errors and efficient estimation. Behavior Genetics 31 (2): 179-191. 
Kohler, H.-P., K. Christensen, A. Skytthe, and L. B. Knudsen (2002). The fertility pattern of twins and the general population compared: Evidence from Danish cohorts 1945-64. Demographic Research 6, Article 14.

Lundin, Susanne (1996). Makten över kroppen. In Lundin, Susanne, Lynn Åkesson (red.), Kroppens tid, identitet och samhälle. Natur och Kultur.

Madrigal, L. (1995). Differential fertility of mothers of twins and mothers of singletons: study in Limon, Costa Rica. Human Biology 67 (5): 779-787.

Murphy, M.; K. Hey; J. Brown; B. Willis; J. D. Ellis; D. Barlow (1997, 1998). Infertility treatment and multiple birth rates in Britain, 1938-94. Journal of Biosocial Science 29: 235-243, and 30: 128-131.

Oleszczuk, Jaroslaw J.; Donald M. Keith; Louis G. Keith (1999). Projections of population-based twinning rates through the year 2100. Journal of Reproductive Medicine 44 (11): 913-921.

Pollard, G.N. (1969). Multiple births in Australia, 1944-63. Journal of Biosocial Science 1: 389-404.

Rodgers, J.C., H.-P. Kohler, K. O. Kyvik, and K. Christensen (2001). Behavior genetic modeling of human fertility: findings from a contemporary Danish twin study. Demography 38 (1): 29-42.

Rosenzweig, Mark R. and Kenneth I. Wolpin (1980). Testing the Quantity-Quality fertility model: the use of twins as a natural experiment. Econometrica 48: 227-240.

Socialstyrelsen (1998). Förlossningar och barn födda efter provrörsbefruktningar 1982-1995. Stockholm: The (Swedish) National Board of Health and Welfare; SoS-rapport 1998:7.

Statistiska centralbyrån (SCB). Folkmängdens förändringar 1965. Stockholm: Statistics Sweden.

Statistiska centralbyrån (SCB). Annual publications of population statistics. Stockholm: Statistics Sweden.

Steegers-Theunissen, Régine P. M.; Werner M. Zwertbroek,; Anjoke J. M. Huisjes; Humphrey H. Kanhai; Hein W. Bruinse ; and Hans M. W. M. Merkus (1998). Multiple birth prevalence in the Netherlands: impact of maternal age and assisted reproductive techniques. Journal of Reproductive Medicine 43 (3): 173179. 
Strandberg, Margit and Jan M. Hoem (2002). Patterns of twinning for Swedish women, 1961-1999. MPIDR Working Paper. Download from http://www.demogr.mpg.de/papers/working/wp-2002-031.pdf.

Tas, R. F. J. (1994). Multiple births in the Netherlands, 1900-1993. [Meerlingen in Nederland, 1900-1993.] Maandstatistiek van de Bevolking 42 (2): 20-21.

Terzera, Laura (2002). The evolution of multiple births in Italy. Genus 58 (1): 159-181.

Tomassini, C., F. C. Billari, A. Rosina, and K. Christensen (2001). Born together-die together. Live together-die together. The role of the partner and of the co-twin on longevity at very old ages. Genus 57 (3-4): 63-82.

Walke, Rainer (2002). Twins or two single children: The influence of the multiplicity of the first birth on the divorce risk of Swedish women. Demographic Research 7, Article 9.

Wienke, A., N. V. Holm, A. Skytthe, A., and A. I. Yashin (2001). The heritability of mortality due to heart disease: a correlated frailty model applied to Danish twins. Twin Research 4 (4): 266-274.

Wienke, A., K. Christensen, A. Skytthe, A. I. Yashin (2002). Genetic analysis of cause of death in a mixture model of bivariate lifetime data. Statistical Modelling 2 (2): 89-102.

Yashin, A.I., I. A. Iachine, and A. Z. Begun (1998). New models for survival studies of twins. Behavior Genetics 28 (6): 486.

Yashin, A.I., I. A. Iachine, and A. Z. Begun (1999a). Genetics of human susceptibility to death and longevity: findings from twin studies. Zeitschrift für Gerontologie und Geriatrie 32:Supplement 2, II/129.

Yashin, A.I. , I. A. Iachine, and J. R. Harris (1999b). Half of variation in susceptibility to mortality is genetic: findings from Swedish twin survival data. Behavior Genetics 29 (1): 11-20. 


\section{Tables and figures}

Table 1: $\quad$ Singleton birth or twin birth in the first confinement; relative risks for childless Swedish women

\begin{tabular}{lll|lll}
$\begin{array}{l}\text { Singleton } \\
\text { Twin birth }\end{array}$ & $0.0093^{\mathrm{a}}$ & \multicolumn{2}{l}{} \\
\hline Period $^{\mathrm{b}}$ & Singleton & Twin birth & Age $^{\mathrm{c}}$ & Singleton & Twin birth \\
\hline $1961-63$ & 1.461 & 0.0095 & $15-18$ & 0.071 & 0.0004 \\
$1964-66$ & 1.613 & 0.0109 & $19-21$ & 0.376 & 0.0021 \\
$1967-69$ & 1.440 & 0.0090 & $22-24$ & 0.664 & 0.0047 \\
$1970-72$ & 1.364 & 0.0092 & $25-27$ & 0.964 & 0.0087 \\
$1973-75$ & 1.323 & 0.0091 & $28-30$ & 1.000 & 0.0116 \\
$1976-78$ & 1.080 & 0.0075 & $31-33$ & 0.752 & 0.0124 \\
$1979-81$ & 0.972 & 0.0079 & $34-36$ & 0.445 & 0.0094 \\
$1982-84$ & 0.868 & 0.0076 & $37-39$ & 0.223 & 0.0053 \\
$1985-87$ & 0.891 & 0.0083 & $40-42$ & 0.085 & 0.0016 \\
$1988-90$ & 1.000 & 0.0103 & $43-45$ & 0.019 & 0.0003 \\
$1991-93$ & 0.950 & 0.0129 & $46-$ & 0.001 & 0.0000 \\
$1994-96$ & 0.778 & 0.0128 & & & \\
$1997-99$ & 0.674 & 0.0128 & & & \\
\hline
\end{tabular}

a) Standardized for calendar period and mother's current age.

b) Standardized for mother's age.

c) Standardized for calendar period.

Table 2: Singleton birth or twin birth in the second confinement; relative risks for Swedish women according to the multiplicity of their first birth

\begin{tabular}{lll}
\hline & \multicolumn{2}{l}{ Second confinement } \\
\cline { 2 - 3 } First confinement & Singleton & Twin birth \\
\hline Singleton & 1 & 0.0102 \\
Twin birth & 0.3382 & 0.0074 \\
\hline
\end{tabular}

Standardized for mother's age at first birth, current calendar period, and time since first birth (given in Table 3). 
Table 3: $\quad$ Second confinement; relative risks for Swedish mothers according to the multiplicity of their first birth

First confinement:

Singleton

1

Twin birth $^{\mathrm{a}}$ 0.342

\begin{tabular}{|c|c|c|c|c|c|c|c|c|}
\hline \multirow[b]{2}{*}{ Period $^{b}$} & \multicolumn{2}{|c|}{ First confinement } & \multirow[b]{2}{*}{$\begin{array}{l}\text { Age at } \\
\text { first } \\
\text { birth }^{c}\end{array}$} & \multicolumn{2}{|c|}{ First confinement } & \multirow{2}{*}{$\begin{array}{l}\text { Months } \\
\text { since } \\
\text { first } \\
\text { birth }^{d}\end{array}$} & \multicolumn{2}{|c|}{ First confinement } \\
\hline & Singleton & $\begin{array}{l}\text { Twin } \\
\text { birth }\end{array}$ & & Singleton & $\begin{array}{l}\text { Twin } \\
\text { birth }\end{array}$ & & Singleton & Twin birth \\
\hline $1961-63$ & 0.650 & 0.280 & $15-18$ & 1.026 & 0.626 & $0-11$ & 0.006 & 0.005 \\
\hline $1964-66$ & 0.746 & 0.345 & $19-21$ & 1.123 & 0.577 & $12-17$ & 0.249 & 0.127 \\
\hline $1967-69$ & 0.654 & 0.253 & $22-24$ & 1.198 & 0.451 & $18-23$ & 0.652 & 0.187 \\
\hline $1970-72$ & 0.636 & 0.249 & $25-27$ & 1.171 & 0.363 & $24-29$ & 0.929 & 0.227 \\
\hline $1973-75$ & 0.642 & 0.249 & $28-30$ & 1.000 & 0.269 & $30-35$ & 1.000 & 0.240 \\
\hline 1976-78 & 0.609 & 0.207 & $31-33$ & 0.748 & 0.204 & $36-47$ & 0.965 & 0.247 \\
\hline $1979-81$ & 0.667 & 0.224 & $34-36$ & 0.481 & 0.102 & $48-59$ & 0.725 & 0.267 \\
\hline $1982-84$ & 0.714 & 0.251 & $37-39$ & 0.267 & 0.060 & $60-83$ & 0.438 & 0.207 \\
\hline $1985-87$ & 0.842 & 0.307 & $40-42$ & 0.115 & 0.049 & $84-107$ & 0.234 & 0.128 \\
\hline $1988-90$ & 1.000 & 0.331 & $43-45$ & 0.035 & & $108-120$ & 0.131 & 0.071 \\
\hline 1991-93 & 1.003 & 0.338 & $46-$ & 0.007 & & & & \\
\hline $1994-96$ & 0.876 & 0.246 & & & & & & \\
\hline 1997-99 & 0.803 & 0.196 & & & & & & \\
\hline
\end{tabular}

a) Standardized for calendar period, mother's age at first birth, and time since first birth.

b) Standardized for mother's and first child's age.

c) Standardized for period and months since first birth.

d) Standardized for period and mother's age. 
Table 4: $\quad$ Third child; relative risks for Swedish mothers according to whether they had their first two children as one pair of twins or as two singletons

First two confinements:

Two singletons 1 One twin birth $^{\mathrm{a}} \quad 1.010$

\begin{tabular}{|c|c|c|c|c|c|c|c|c|}
\hline \multirow[b]{2}{*}{ Period $^{b}$} & \multicolumn{2}{|c|}{$\begin{array}{l}\text { First two } \\
\text { confinements }\end{array}$} & \multirow{2}{*}{$\begin{array}{l}\text { Age at first } \\
\text { birth }^{c}\end{array}$} & \multicolumn{2}{|c|}{$\begin{array}{l}\text { First two } \\
\text { confinements }\end{array}$} & \multirow{2}{*}{$\begin{array}{l}\text { Years } \\
\text { since } \\
\text { previous } \\
\text { birth }^{\text {de }}\end{array}$} & \multicolumn{2}{|c|}{$\begin{array}{l}\text { First two } \\
\text { confinements }\end{array}$} \\
\hline & $\begin{array}{l}\text { Two } \\
\text { singletons }\end{array}$ & $\begin{array}{l}\text { One twin } \\
\text { birth }\end{array}$ & & $\begin{array}{l}\text { Two } \\
\text { singletons }\end{array}$ & $\begin{array}{l}\text { One twin } \\
\text { birth }\end{array}$ & & $\begin{array}{l}\text { Two } \\
\text { singletons }\end{array}$ & $\begin{array}{l}\text { One twin } \\
\text { birth }\end{array}$ \\
\hline 1961-63 & 0.880 & 0.724 & $15-18$ & 3.322 & 2.502 & 0 & 0.015 & 0.019 \\
\hline 1964-66 & 0.939 & 0.885 & $19-21$ & 2.561 & 2.286 & 1 & 0.524 & 0.483 \\
\hline $1967-69$ & 0.687 & 0.630 & $22-24$ & 1.864 & 1.831 & 1.5 & 0.936 & 0.712 \\
\hline $1970-72$ & 0.583 & 0.610 & $25-27$ & 1.365 & 1.492 & 2 & 1.031 & 0.869 \\
\hline $1973-75$ & 0.551 & 0.623 & 28-30 & 1.000 & 1.123 & 2.5 & 1.000 & 0.923 \\
\hline 1976-78 & 0.468 & 0.531 & $31-33$ & 0.714 & 0.870 & 3 & 0.967 & 0.958 \\
\hline $1979-81$ & 0.585 & 0.581 & $34-36$ & 0.485 & 0.445 & 4 & 0.938 & 1.037 \\
\hline 1982-84 & 0.664 & 0.675 & 37-39 & 0.309 & 0.272 & $5-6$ & 0.698 & 0.806 \\
\hline $1985-87$ & 0.843 & 0.862 & $40-42$ & 0.150 & 0.216 & 7-8 & 0.412 & 0.496 \\
\hline $1988-90$ & 1.000 & 0.970 & 43-45 & 0.043 & 0 & $9-10$ & 0.230 & 0.276 \\
\hline 1991-93 & 0.995 & 1.021 & $46+$ & 0.027 & 0 & & & \\
\hline 1994-96 & 0.719 & 0.771 & & & & & & \\
\hline $1997-99$ & 0.588 & 0.631 & & & & & & \\
\hline
\end{tabular}

a) b) c) d) See Table 3, mutatis mutandi.

e) For definition in months, see Table 3. 
Table 5: $\quad$ Fourth child; relative risks for mothers of one set of twins and one singleton

Previous confinements:

\begin{tabular}{|c|c|c|c|c|c|c|c|c|}
\hline \multirow{3}{*}{\multicolumn{3}{|c|}{$\begin{array}{l}\text { Singleton and then twins } \\
\text { Twins and then singleton } \\
\text { Previous births }\end{array}$}} & \multirow{2}{*}{\multicolumn{6}{|c|}{$\begin{array}{l}1 \\
1.982\end{array}$}} \\
\hline & & & & & & & & \\
\hline & & & & Previous & births & & Previous $b$ & irths \\
\hline Period & $\begin{array}{l}\text { Singleton } \\
\text { and then } \\
\text { twins }\end{array}$ & $\begin{array}{l}\text { Twins and } \\
\text { then } \\
\text { singleton }\end{array}$ & $\begin{array}{l}\text { Age at } \\
\text { second } \\
\text { birth }\end{array}$ & $\begin{array}{l}\text { Singleton } \\
\text { and then } \\
\text { twins }\end{array}$ & $\begin{array}{l}\text { Twins and } \\
\text { then } \\
\text { singleton }\end{array}$ & $\begin{array}{l}\text { Years } \\
\text { since } \\
\text { previous } \\
\text { birth }\end{array}$ & $\begin{array}{l}\text { Singleton } \\
\text { and then } \\
\text { twins }\end{array}$ & $\begin{array}{l}\text { Twins and } \\
\text { then } \\
\text { singleton }\end{array}$ \\
\hline 1961-63 & 1.218 & 1.721 & -18 & 6.133 & 13.849 & 0 & 0.031 & 0.073 \\
\hline $1964-66$ & 1.113 & 1.908 & $19-21$ & 4.587 & 5.225 & 1 & 0.876 & 1.887 \\
\hline $1967-69$ & 0.782 & 1.375 & $22-24$ & 2.482 & 4.734 & 1.5 & 1.137 & 3.370 \\
\hline $1970-72$ & 0.534 & 1.338 & $25-27$ & 1.610 & 3.427 & 2 & 1.453 & 3.125 \\
\hline $1973-75$ & 0.531 & 1.166 & $28-30$ & 1.000 & 2.280 & 2.5 & 1.000 & 2.313 \\
\hline $1976-78$ & 0.427 & 0.895 & $31-33$ & 0.798 & 1.518 & 3 & 1.042 & 2.778 \\
\hline $1979-81$ & 0.544 & 1.203 & $34-36$ & 0.569 & 1.202 & 4 & 1.203 & 2.196 \\
\hline 1982-84 & 0.579 & 1.275 & 37-39 & 0.257 & 0.890 & $5-6$ & 1.076 & 1.724 \\
\hline $1985-87$ & 0.840 & 1.490 & $40-42$ & 0.073 & 0.771 & 7-8 & 0.783 & 1.045 \\
\hline $1988-90$ & 1 & 2.060 & $43-45$ & 0 & 1.303 & $9-10$ & 0.446 & 0.759 \\
\hline $1991-93$ & 0.916 & 2.172 & & & & & & \\
\hline $1994-96$ & 0.697 & 1.291 & & & & & & \\
\hline $1997-99$ & 0.531 & 1.085 & & & & & & \\
\hline
\end{tabular}

See Table 3, mutatis mutandi. 
Twin births per 1000 births

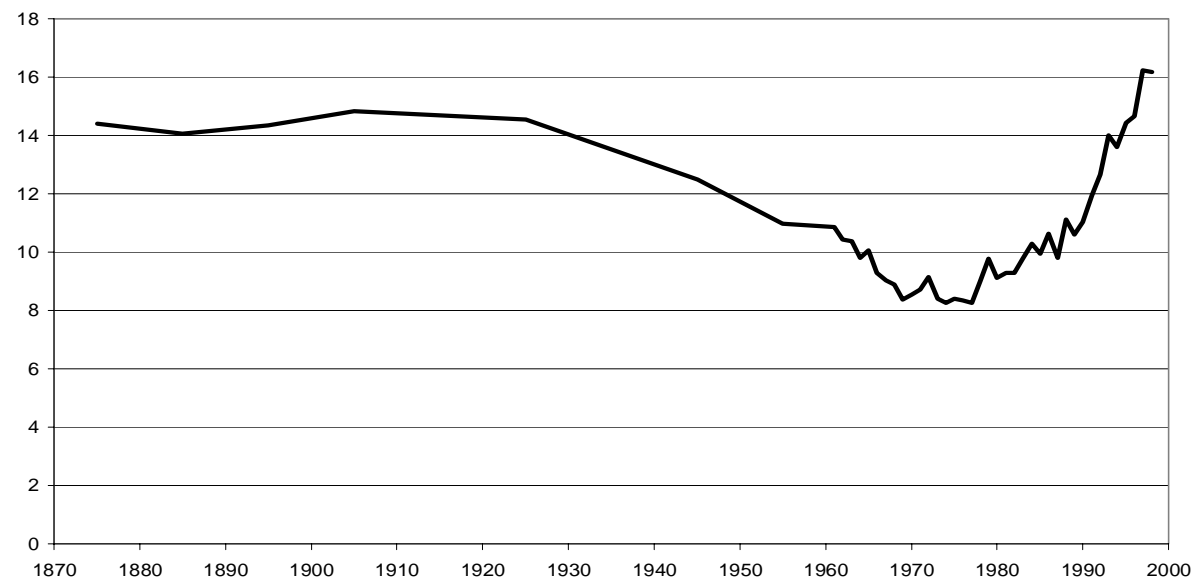

Figure 1: $\quad$ Swedish twinning rates, 1871-1998

Note. The fraction of twin births is computed as the number of twin births (counting live and still births) divided by the total number of births in each year.

Sources:

For years 1871-1965: Folkmängdens förändringar 1965, tabell 7:3 (SCB 1965),

For years 1955-1998: Annual publications of population statistics (SCB). 


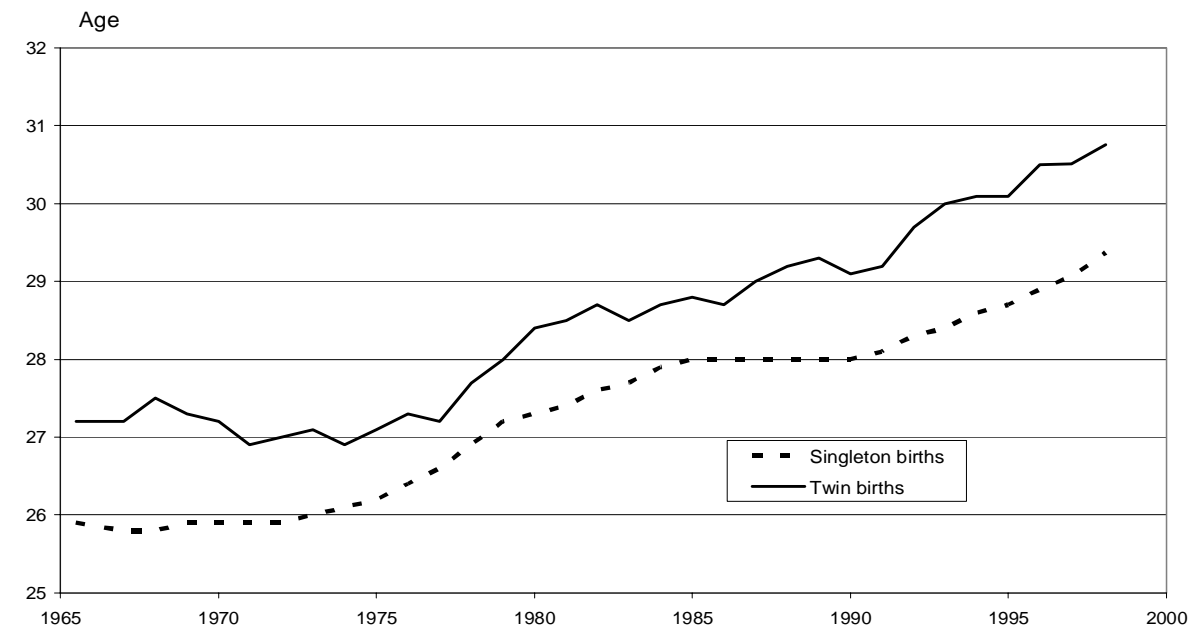

Figure 2: $\quad$ Mean age of mother at birth

Sources: Annual publications of population statistics (SCB). 


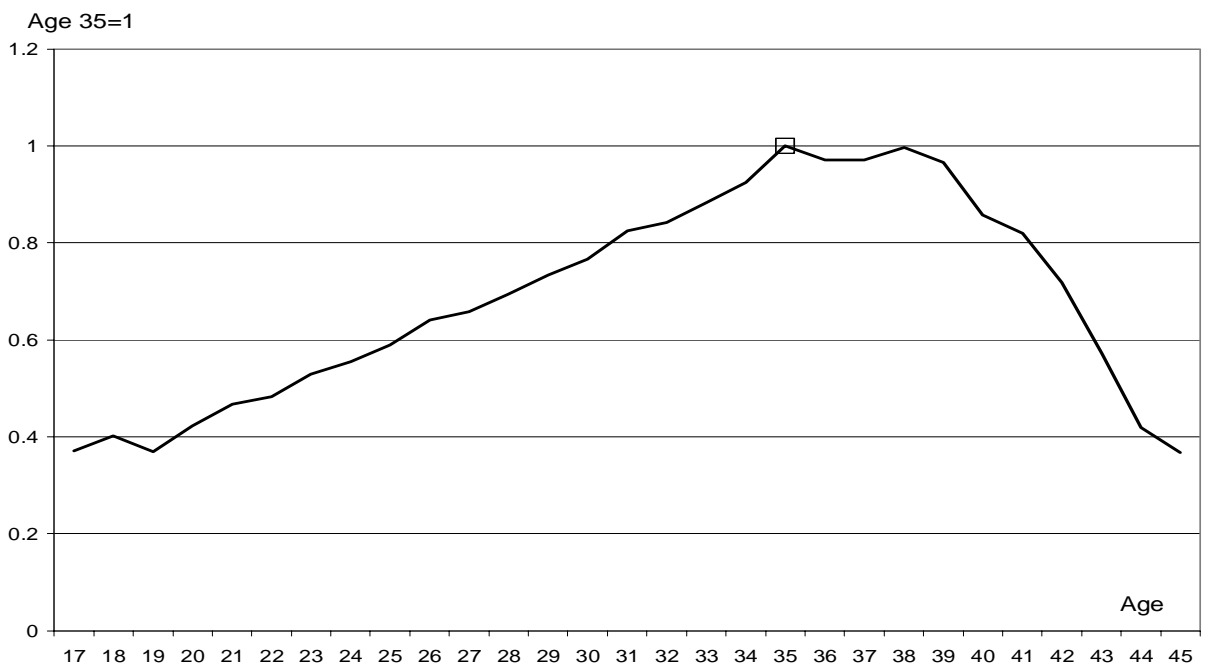

Figure 3: $\quad$ Index of the twinning rate by age

Note. Standardized for calendar year, 1961-98

Sources: Annual publications of population statistics (SCB) 


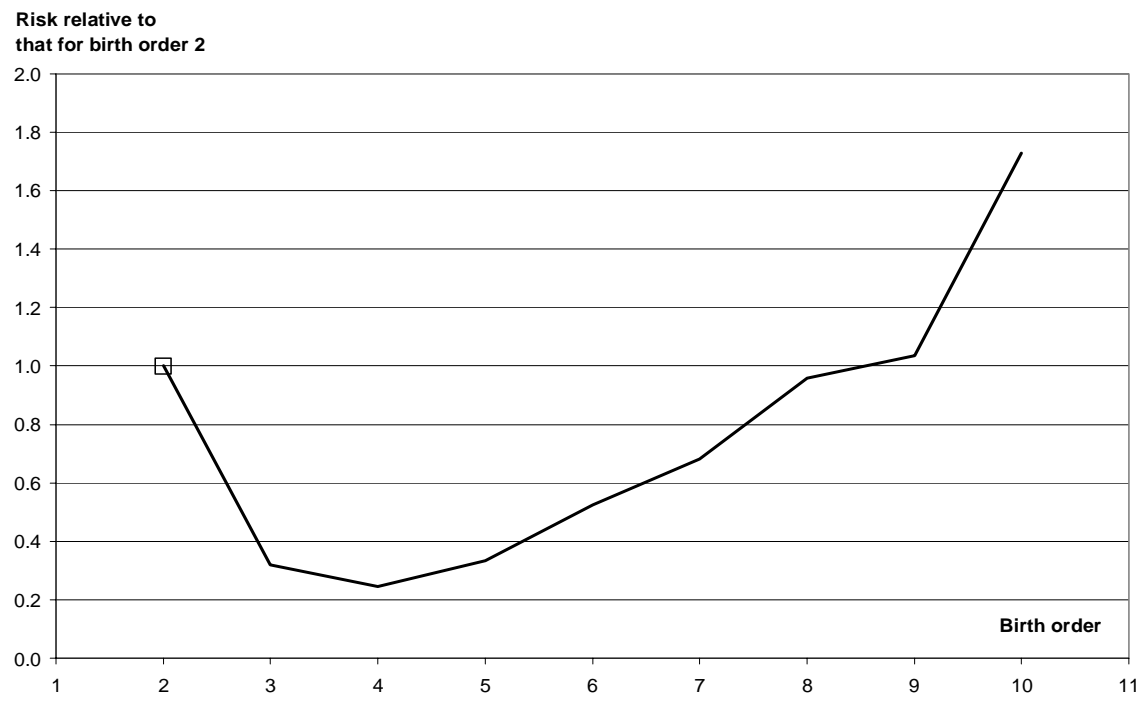

Figure 4: $\quad$ Risk of a first twin birth, by order of birth

Note: Standardized for calendar period, woman's age at last previous birth, and months since last previous birth. Source: Our calculations based on the Swedish population register, data for 1961-99. 


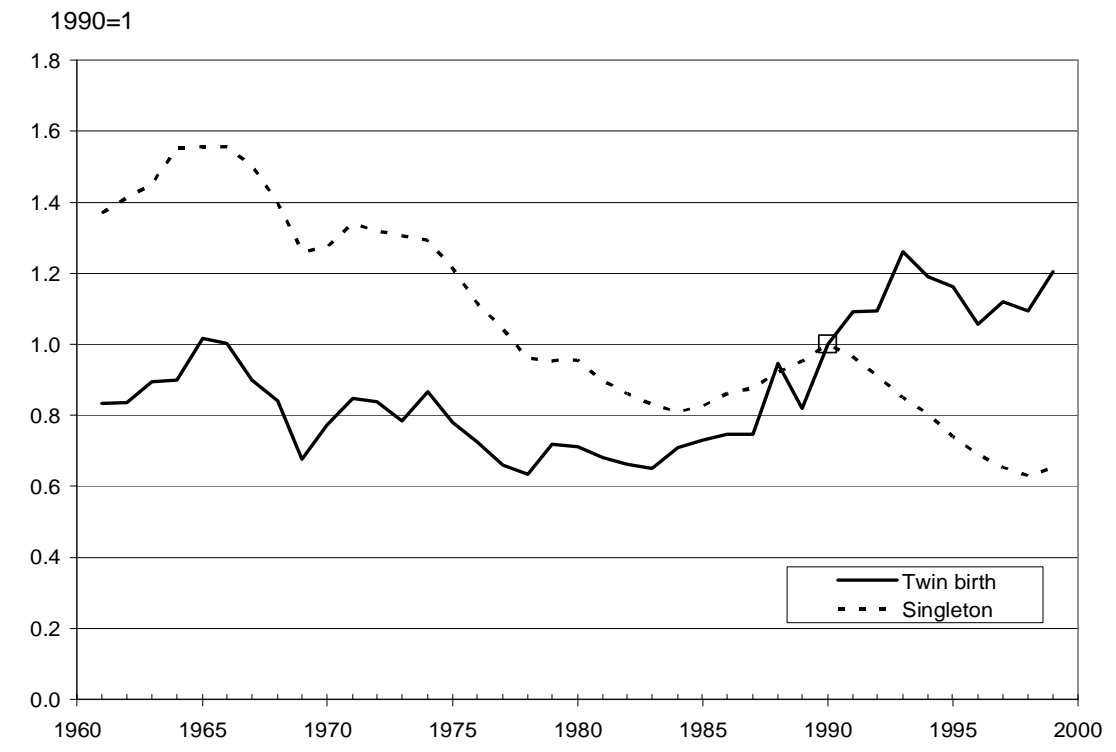

Figure 5: $\quad$ First birth; annual index for singleton and twin births, separately Note. Standardized for age.

Source: Our computations based on Table 1. 


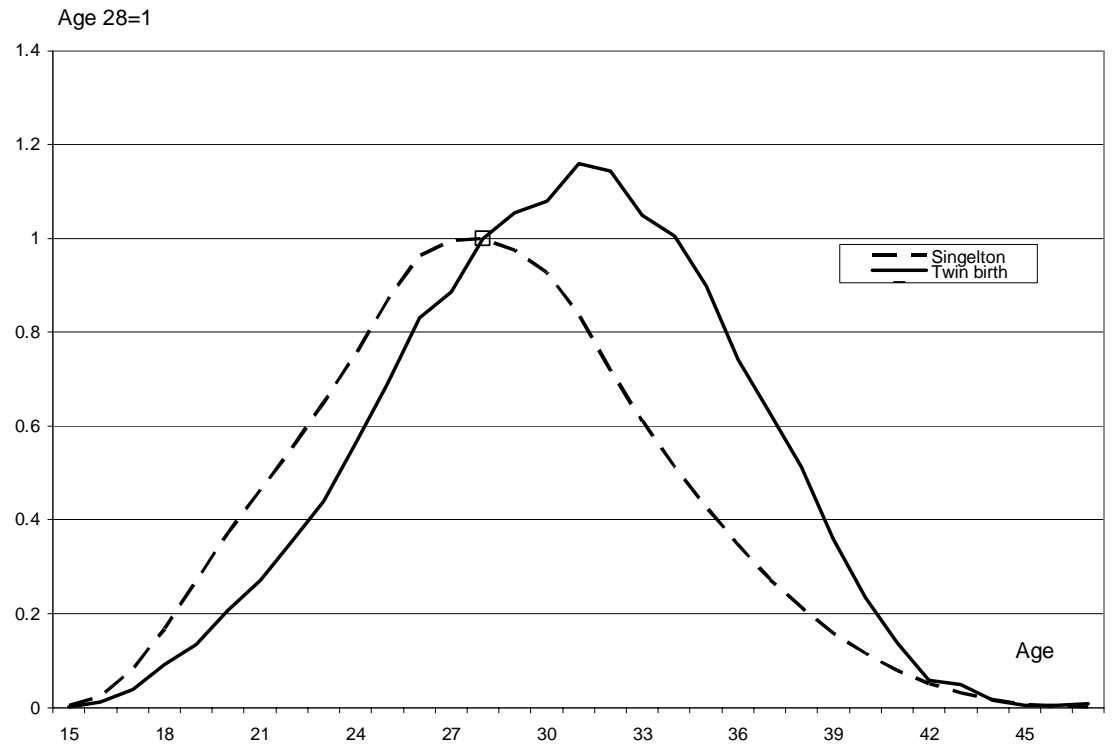

Figure 6: First birth; age profile of intensities of singleton and twin birth, separately

Note. Standardized for calendar period.

Source: Our calculations based on the data for table 1, single years of age. 


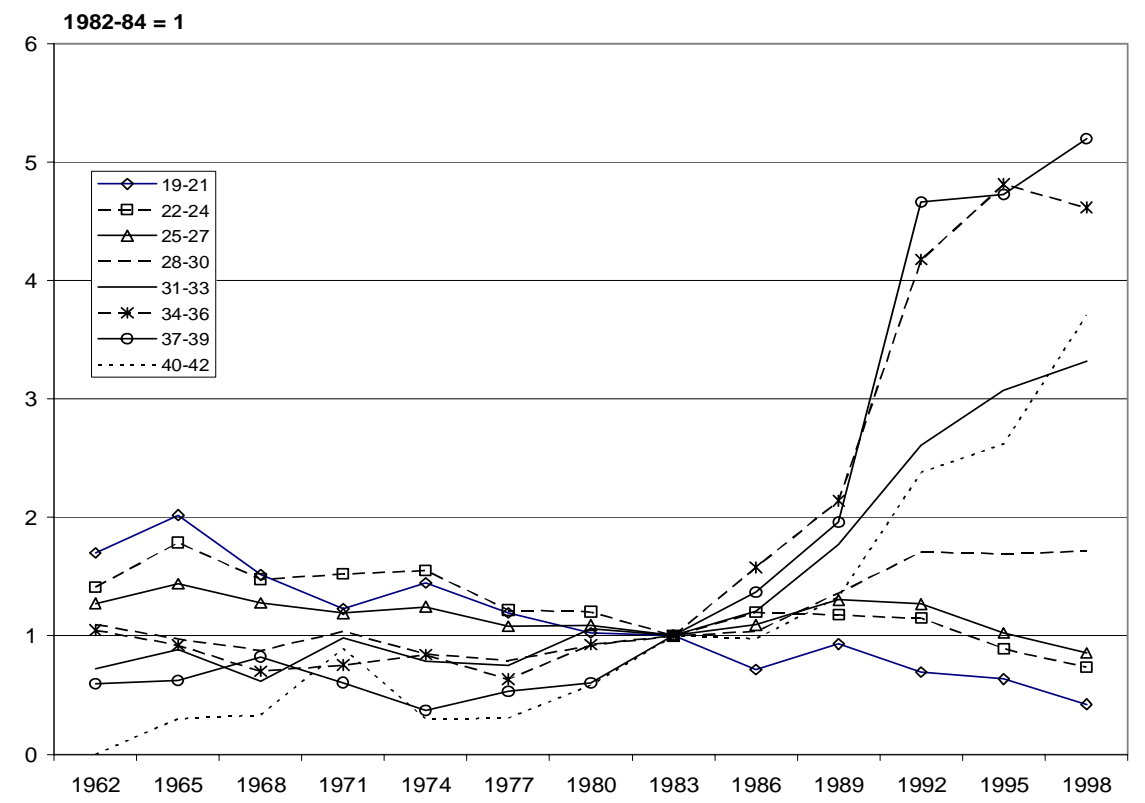

Figure 7: $\quad$ Trends in the risk that the first birth results in twins for selected age groups, relative to the risk in 1982-84. Period 1961-1999 


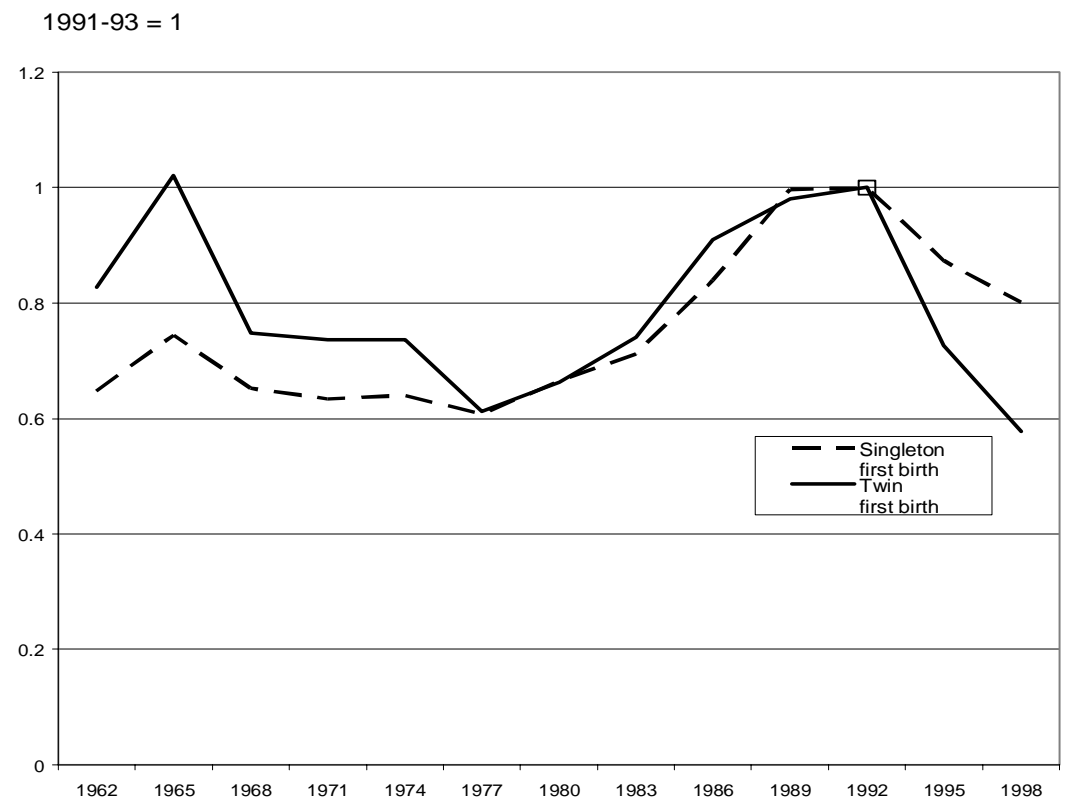

Figure 8: $\quad$ Second birth; annual index for mothers with a singleton or a twin first birth, separately

Note. Three-year calendar periods. Standardized for the mother's age at first birth and for time since that birth. Source: Our calculations based on Table 3. 


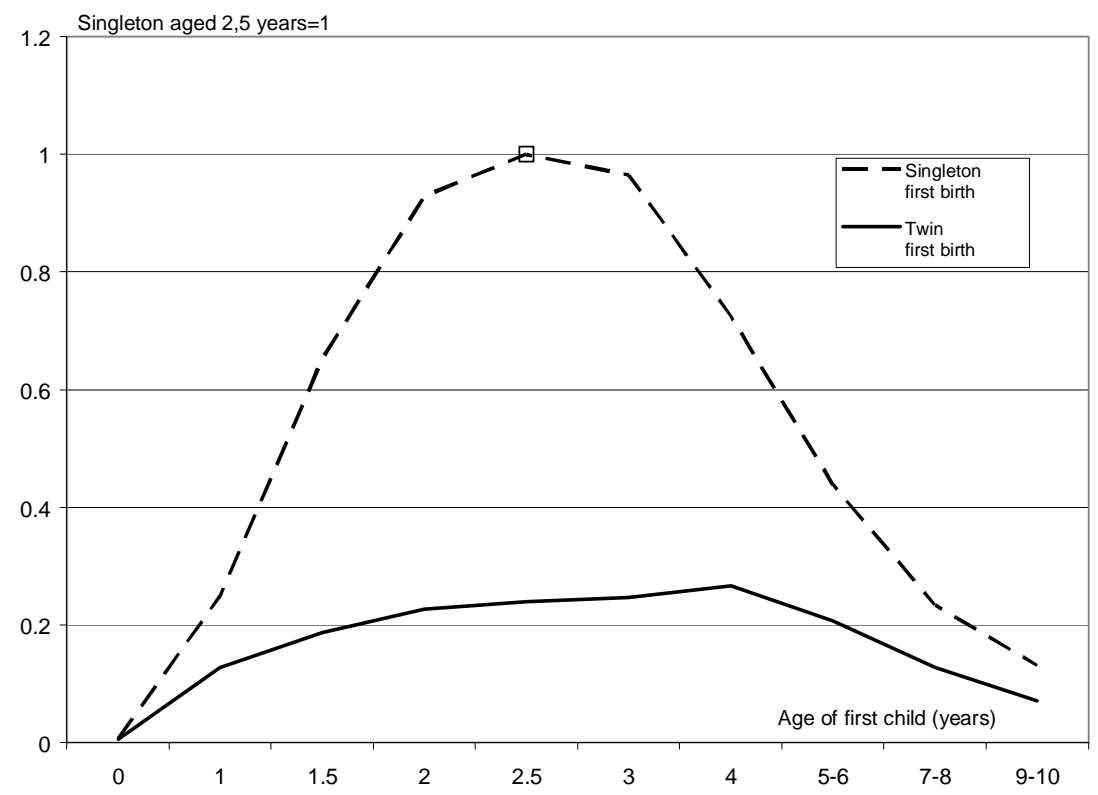

Figure 9: $\quad$ Second birth; duration profiles for mothers with a singleton or a twin first birth, separately

Note. Standardized for calendar period and for woman's age at first birth.

Source: Table 3. 


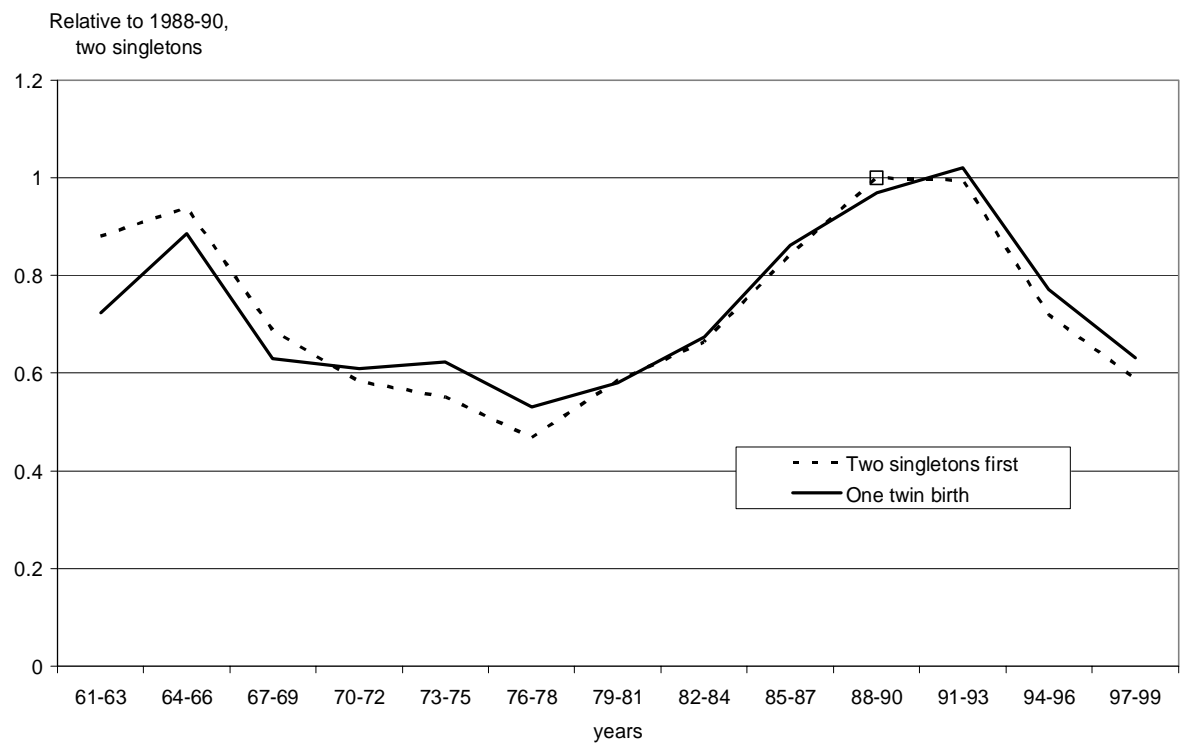

Figure 10: Third child; annual index for mothers with one twin birth vs. with two singletons

Note. Three-year calendar periods. Standardized for the mother's age at previous birth and for time since that birth.

Source: Table 4. 


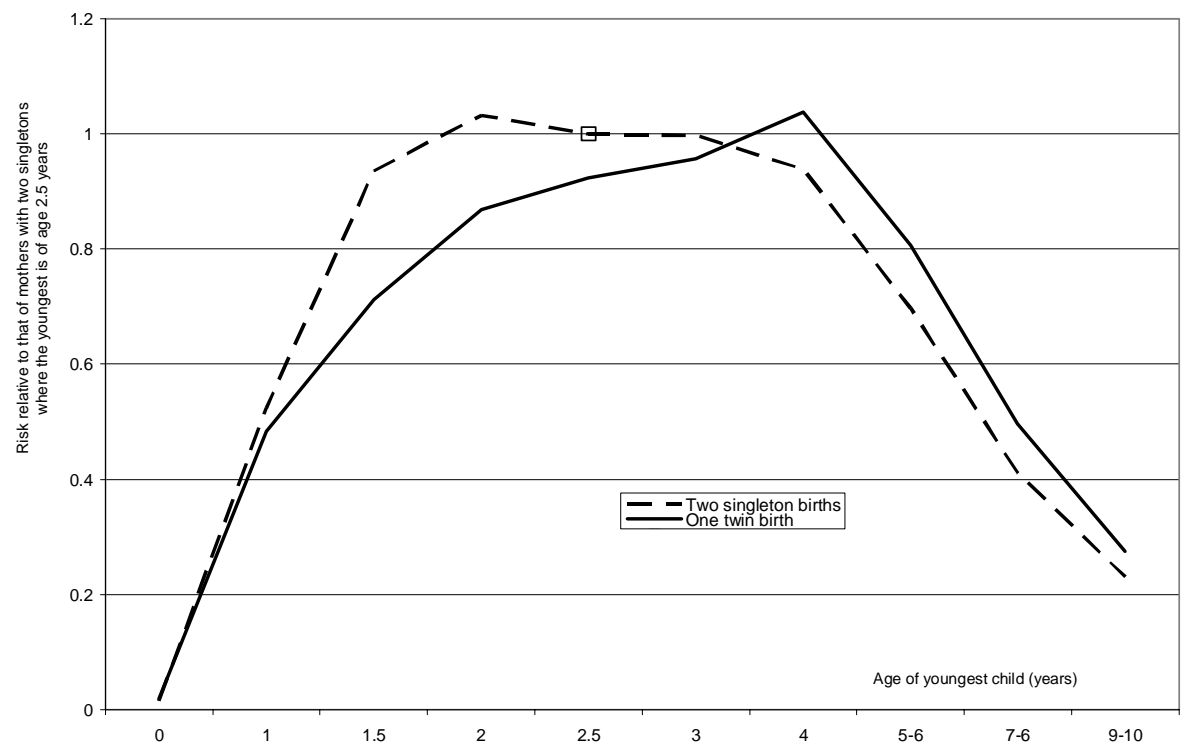

Figure 11: Third child; duration profile for mothers with one set of twins and for mothers with two singletons

Note. Standardized for calendar period and for woman's age at previous birth.

Source: Table 4. 


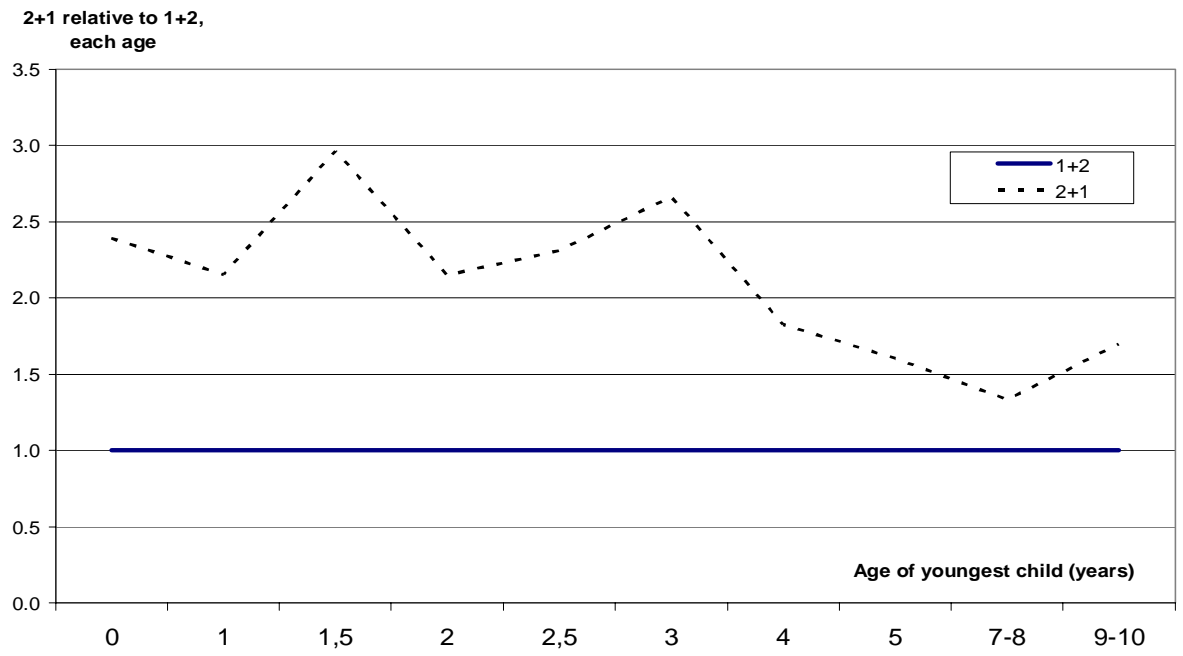

Figure 12: Fourth child; relative risks for mothers with a singleton and then twins $(1+2) v s$. mothers with twins and then a singleton $(2+1)$

Note. Standardized for calendar period and for the woman's age at second confinement. Source: Our computations based on Table 5. 
Demographic Research - Volume 11, Article 15 